\title{
Tracking New Challenges of Nutrition Transition and Developing Specific Strategies to Promote Healthy China
}

\author{
Gangqiang Ding ${ }^{1, \#}$
}

With the rapid socioeconomic development, urbanization and population aging, China has been experiencing the nutrition transition characterized as a double burden of undernutrition and over-nutrition (1-2). Actively responding to the challenges, the Chinese government has released a series of national nutrition and health policies during the past five years, such as the Healthy China 2030 Blueprint, Healthy China Initiative (2019-2030), and National Nutrition Plan (2017-2030), in the context of comprehensive implementation of the National Strategy for Healthy China (3-5).

The national nutrition survey has been implemented regularly to track dynamics of nutrition and health status in the Chinese population. Until now six rounds of national nutrition surveys had been conducted among Chinese residents in 1959, 1982, 1992, 2002, 2010-2013, and 2015-2017 (6-11). The surveys of 1959 and 1982 were completed by national nutrition project team in Chinese Academy of Medical Sciences, and the rest cycles were conducted by China CDC (Former Chinese Academy of Preventive Medicine). The nationally representative samples were selected using a multistage cluster random sampling method in the surveys. The fourth survey in 2002, renamed the China National Nutrition and Health Survey, combined with chronic diseases and nutrition for the first time (8). Given the rapid change of diet, nutrition, and other lifestyle factors in China, the nutrition survey was renamed to nutrition surveillance since 2010-2013 and are scheduled to be conducted every 3-5 years (9). Remarkably, the latest China Nutrition and Health Surveillance (2015-2017) has both national and provincial representativeness. All above surveys have provided solid data base of scientific evidence for policymaking in China.

China has been faced with a great challenge of the double burden of malnutrition over time. Stunting, underweight, micronutrient deficiency, overweight and obesity, and nutrition-related chronic diseases are still prevalent among urban and rural residents in China. Beginning with comprehensive introduction of the implementation scheme of the China Nutrition and Health Survey/Surveillance, this issue and awaiting issue will publish a series of articles covering topics from dietary intake, sugar-sweetened beverages, serum ferritin, vitamin A, folic acid, weight status, and related self-perception. These articles will give a multidimensional assessment of diet, nutrition, and health status mong school-aged students, women of childbearing age, pregnant women, the elderly and potential sociodemographic disparity.

Three papers will describe the consumption and features of energy, macronutrients, vitamins, and beverages among children and adolescents. The dietary intake of children can affect their life-long health.

Iron deficiency and vitamin A deficiency in childhood have the potential adverse short- and longterm impacts on their health. One article was about the prevalence of iron deficiency among Chinese children in 2016-2017, especially among girls aged 12-17 years. Another article discussed the prevalence of vitamin A marginal deficiency among rural children was higher than that among urban children in China, especially among younger children. For pregnant Chinese women, one article reported that there was still a certain proportion of women at risk of folic acid deficiency in 2015.

Underweight is an independent risk factor of their health and life quality among the elderly. One article will present trend of the underweight status among elderly people from 1992 to 2015. Precise selfperception of body weight status plays a key role in optimal weight control against underweight or overweight. Another study will show the percentage of self-perception of body weight accurately in Chinese women of childbearing age.

Findings from the aforementioned papers have important implications for policymaking, strategy development, and public health practice. Effective strategies should be actively implemented to cope with new challenges during rapid nutrition transition. It is vital to transfer each policy into action, develop better measures and practice for promoting balanced diets 
and healthy lifestyles, and enhancing nutrition awareness and technology. Joint efforts of governments, societies, schools, families, and individuals should be promoted to establish supportive environments for nutrition and health promotion.

doi: $10.46234 / \mathrm{ccdcw} 2021.054$

\# Corresponding author: Gangqiang Ding, dinggq@chinacdc.cn.

${ }^{1}$ National Institute for Nutrition and Health, Chinese Center for Disease Control and Prevention, Beijing, China.

Submitted: February 18, 2021; Accepted: February 25, 2021

\section{REFERENCES}

1. Huang LN, Wang ZH, Wang HJ, Zhao LY, Jiang HR, Zhang B, et al. Nutrition transition and related health challenges over decades in China. Eur J Clin Nutr 2021;75(2):247 - 52. http://dx.doi.org/10. 1038/s41430-020-0674-8.

2. He YN, Li YP, Yang XG, Hemler EC, Fang YH, Zhao LY, et al. The dietary transition and its association with cardiometabolic mortality among Chinese adults, 1982-2012: a cross-sectional population-based study. Lancet Diabetes Endocrinol 2019;7(7):540 - 8. http://dx.doi.org/
10.1016/S2213-8587(19)30152-4

3. The Communist Party of China Central Committee the State Council. Healthy China 2030 blueprint. 2016. http://www.gov.cn/xinwen/201610/25/content_5124174.htm. [2020-12-23]. (In Chinese).

4. Health China Action Promotion Committee. Healthy China initiative (2019-2030). 2019. http://www.gov.cn/xinwen/2019-07/15/content_ 5409694.htm. [2020-12-23]. (In Chinese).

5. Chinese Nutrition Society. National nutrition plan (2017-2030). Acta Nutriments Sinica 2017;39(4):315-20. http://d.wanfangdata.com.cn/ periodical/ChlQZXJpb2RpY2FsQ0hJTmV3UzIwMjEwMTI1EhB5aW 5neXhiMjAxNzA0MDAyGggxZnRxeWtieQ==. (In Chinese).

6. Ge KY, Zhai FY, Yan HC. The third national nutrition survey. J Hyg Res 1996;25(S1):3 - 15. http://dx.doi.org/10.19813/j.cnki.weisheng yanjiu.1996.s1.002. (In Chinese).

7. Ge KY. The dietary and nutritional status of Chinese population. Beijing: People's Medical Publishing House. 1996. (In Chinese).

8. Li LM, Rao KQ, Kong LZ, Yao CH, Xiang HD, Zhai FY, et al. A description on the Chinese national nutrition and health survey in 2002. Chin J Epidemiol 2005;26(7):478 - 84. http://dx.doi.org/10. 3760/j.issn:0254-6450.2005.07.004. (In Chinese).

9. Chang JL, Wang Y. Comprehensive report on China nutrition and health surveillance (2010-2013). Beijing: Peking University Medical Press. 2016. (In Chinese).

10. Yang YX, Ge KY. Encyclopedia of nutrition science. 2nd ed. Beijing: People's Medical Publishing House. 2019. (In Chinese).

11. Yu DM, Zhao LY, Zhao WH. Status and trends in consumption of grains and dietary fiber among Chinese adults (1982-2015). Nutr Rev 2020;78(S1):43 - 53. http://dx.doi.org/10.1093/nutrit/nuz075.

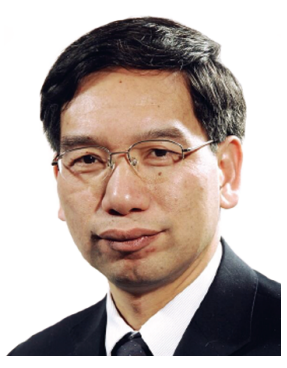

\section{Gangqiang Ding}

Director of Institute for Nutrition and Health, Chinese Center for Disease Control and Prevention

Vice director of Chinese Nutrition Society

Vice director of China Food Science and Technology Society

Vice chairman of Health Communication branch of China Preventive Medicine Society 